\title{
Study of Thermal and Oxidative Stability of Cottonseed Biodiesel
} Cynthia Fraga Scofield ${ }^{* 1}$, Thiago V. Rodrigues ${ }^{1}$, Caroline D. Oliveira ${ }^{1}$, e Lucia R. Raddi de Araujo ${ }^{1}$

${ }^{*}$ Physical Chemistry Department, Universidade do Estado do Rio de Janeiro/Chemical Institute, Rio de Janeiro, RJ, Brazil

\begin{abstract}
Biodiesel is a renewable fuel with excellent lubricity and biodegradability. However, its use may be compromised by factors that change its characteristics and occur during production, transportation and/or storage. Some of them are associated with biodiesel stability and can affect vehicle performance. The objective of this work was to analyze the main causes of cottonseed oil biodiesel instability due to the storage process, determining some physicochemical properties as kinematic viscosity, acidity index, refractive index, electrical conductivity as well as ester content, mass of precipitate formed and $\mathrm{pH}$. The acidity and kinematic viscosity of biodiesel from cottonseed oil increase with storage time. The latter suggests the occurrence of a partial oxidation of biodiesel with formation of products that increase its viscosity. Gas chromatography results showed that even after thermo-oxidative treatment, biodiesel samples maintained the minimum ester content required by the ANP (Brazilian National Agency of Petroleum, Natural Gas and Biofuels) and unsaturated bonds tends to be preferentially oxidized over other carbon-carbon bonds. There was no significant influence of light exposure (storage in amber and transparent vials) on the ester content, refractive index and mass of precipitate formed. On the other hand, the latter was influenced by the heating time.
\end{abstract}

Keywords: Biodiesel, Cottonseed Oil, Stability, Physicochemical Properties

\section{INTRODUCTION}

Road transportation has been the preference for transport of goods in Brazil and generates a high demand for diesel oil. According to the ANP (Brazilian National Agency of Petroleum, Natural Gas and Biofuels), diesel consumption represents about $44 \%$ of the total volume of fuel commercialized in Brazil, showing its importance to the Brazilian energy matrix. However, its use is associated with environmental problems as it is responsible for atmospheric emissions of $\mathrm{CO}_{2}, \mathrm{NO}_{x}$ and $\mathrm{SO}_{2}$. At the same time, the environmental restrictions imposed on fossil fuel users have been increasingly strong, notably with regard to the generation of greenhouse gases. So, the search for renewable fuels is increasingly important. Biodiesel is a biodegradable and renewable energy source, whose sustainable use generates less potential for damage to the environment. The main constituents of biodiesel are alkyl esters of oils and fats that can be obtained by transesterification of triglycerides. Biodiesel provides lubrication enhancing effects on diesel, is safer to store and handle due to its higher flash point. However, due to their lower oxidative stability, its standard specifications may change due to modifications that 
may occur during production, transportation and/or storage. This lower stability is related to the content of unsaturated esters that can be easily oxidized, yielding degradation products such as acids, aldehydes, and polymers (1). These compounds not only compromise fuel properties but also affect engine performance. The negative effect of the degree of unsaturation on oxidative and fluid stability has been reported in the literature (2-6).

The stability of biodiesel is influenced by factors such as temperature, humidity, contact with certain metals and exposure to air and light. Parameters such as kinematic viscosity, acidity index, ester content and peroxide index no longer meet biodiesel commercialization specifications with the evolution of oxidation as a function of time (7-12).

Several methodologies have been developed or adapted to determine the factors associated with biodiesel stability. However, the mechanisms of action and the degree of influence of each of these factors on the biodiesel degradation process are not fully known. These methodologies generally aim to evaluate one of the following aspects: analysis of primary oxidation products, analysis of secondary oxidation products or analysis of changes in the physicochemical properties of biodiesel. As can be seen, the study of the stability of biodiesel is a very relevant topic and is object of study of this work. In this context, the effects of storage and oxidation conditions of biodiesel on acidity, viscosity, ester content and refractive index were investigated.

\section{METHODS AND MATERIAL}

\section{A. Biodiesel production}

Biodiesel was produced by transesterification of commercial cottonseed oil using P.A. ethyl alcohol (alcohol $/$ oil molar ratio $=6 / 1$ ) and sodium ethanolate as catalyst ( $1 \mathrm{wt} \%$ relative to the amount of oil used).The reaction was carried out in a $1 \mathrm{~L}$ flask under constant stirring and heating, maintained at a constant temperature of $70^{\circ} \mathrm{C}$. The product obtained after 1 hour of reaction was purified by decantation and rotational evaporation.

\section{B. Biodiesel characterization}

\section{Acidity index}

The acidity index is the determination of the amount of free acids per gram of sample and provides direct indication of the presence of free fatty acids and oxidation products in biodiesel. Free fatty acids are responsible for corrosion and can indicate the presence of water in the fuel. The acidity index may increase over time due to biodiesel degradation when in contact with air or water. Isopropanol-toluene solution $(1: 1 \mathrm{v} / \mathrm{v})$ is added to a given mass of sample and titrated against alcoholic $\mathrm{KOH}$ solution using phenolphthalein as an indicator. All data refer to the average of at least three measurements. The maximum limit for the acidity index established by ANP Resolution $45 / 2014$ is $0.50 \mathrm{mg} \mathrm{KOH}$ per gram of sample.

\section{Kinematic viscosity}

Kinematic viscosity is a measure of the flow resistance of a fluid under gravity and is defined as the ratio of the fluid's dynamic viscosity to its specific mass. Viscosity influences the fuel misting stage and its lubrication. It may also be responsible for engine power decrease due to fuel loss caused by low viscosity. Viscosity values were determined with a Cannon-Fenske viscometer immersed in a thermostatic bath at $40{ }^{\circ}$ C. All data presented correspond to the average of at least three measurements. ANP Resolution 45/2014 establishes the values of 3.0 and $6.0 \mathrm{~mm}^{2} / \mathrm{s}$ as lower and upper limiting kinematic viscosity at $40^{\circ} \mathrm{C}$.

\section{Gas chromatography}


The purpose of the determination of ester content by gas chromatography is to specify the minimum amount of fatty acid esters present in B100 biodiesel. The ester content is proportional to biodiesel purity, ensuring a satisfactory yield of the transesterification reaction, also indicating lower presence of contaminants in the product. Quantification of the total ester content present in the biodiesel was obtained by a Varian CP-3800 gas chromatograph with flame ionization detector and CP WAX 52 CB column. The oven temperature was kept isothermal at $200{ }^{\circ} \mathrm{C}$ and $\mathrm{H}_{2}$ was used as a carrier gas. The minimum limit for the ester content established by ANP Resolution 45/2014 is $96.5 \mathrm{wt} \%$.

\section{Storage procedures}

The produced biodiesel samples were stored in amber glass vials with screw caps to check the effects of light exposure on samples. After three and four months of storage, the samples were submitted to thermal oxidative stability tests.

\section{Stability tests}

\section{Precipitate formation}

The stored biodiesel samples were filtered and then heated for a period of 60 or 180 minutes at $150^{\circ} \mathrm{C}$ in an open tube exposed to air. After treatment, the sample was filtered again and light reflectivity at room temperature was measured. The amount of insoluble material formed by the sample degradation process was obtained by the difference between filter paper weights before and after heat treatment using an analytical balance.

\section{Thermo-oxidative stability}

The stored biodiesel samples were subjected to an adaptation of the EN 14112 test, established by ANP Resolution 45/2014 in order to verify the oxidation stability of the biodiesel at $110^{\circ} \mathrm{C}$. For this test, a unit based on the scheme available in the methodology was used with the following modifications of the original EN 14112 test: no purified air stream was used (air was injected through a porous plate coupled to a mini compressor under controlled flow) and a $\mathrm{pH}$ electrode in addition to the conductivity measuring electrode was placed in the container to collect the gases released during the treatment. An additional test was also performed at room temperature to evaluate the influence of temperature on the stability of the sample.

In the adapted method, an air stream was injected into a tube containing a biodiesel sample maintained at a constant temperature of $110^{\circ} \mathrm{C}$.

\section{RESULTS AND DISCUSSION}

\section{A. Acidity index}

Figure 1 shows the variation of the acidity index of biodiesel as a function of the storage time for the sample obtained by ethylic transesterification of cottonseed oil at $70 \stackrel{\circ}{\circ}$. Acidity increases with storage time and after one month of storage is no longer within the ANP standards specifications limits (maximum $=0.5 \mathrm{mg} \mathrm{KOH} / \mathrm{g}$ ).

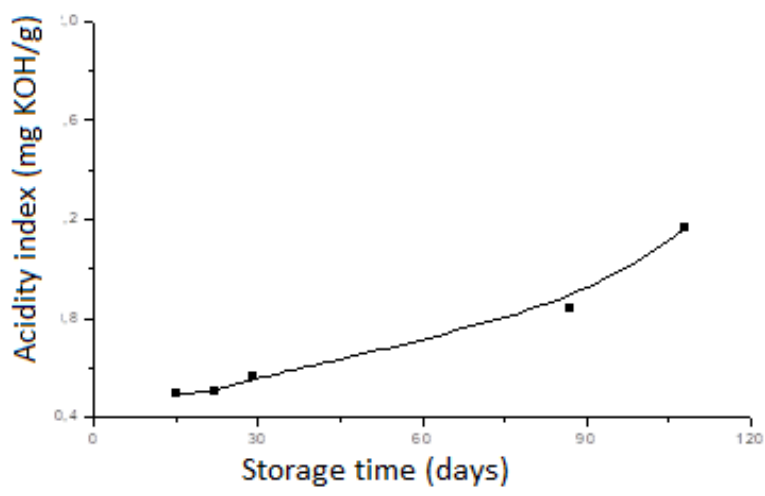

Figure 1: Acidity index as a function of time for biodiesel obtained at $70^{\circ} \mathrm{C}$

When in contact with water or moisture, biodiesel may undergo hydrolytic degradation whereby alkyl esters are hydrolyzed to the corresponding free fatty acids leading to increased acidity (Figure 2).

Water can be present in biodiesel in two forms: dispersed in droplets or solubilized. Unlike diesel oil 
that can have solubilized water contents up to $50 \mathrm{mg} /$ $\mathrm{kg}$, biodiesel absorbs much more moisture and can contain up to $1500 \mathrm{mg} / \mathrm{kg}$ of solubilized water.<smiles></smiles>

Figure 2: Hydrolytic degradation of biodiesel

Although the biodiesel separation process was carried out before storage, it is observed that in practice it is not always possible to completely eliminate water present as an impurity in the starting materials. In addition, some by-products and intermediates of the transesterification reaction, such as monoglycerides, diglycerides and glycerol, favour the emulsification of water in biodiesel making it difficult to be removed.

\section{B. Kinematic viscosity}

Viscosity can be used to evaluate the progress of the oxidation degree, as this reaction can generate compounds that increase product viscosity. The change in viscosity as a function of biodiesel storage time is shown in Figure 3.

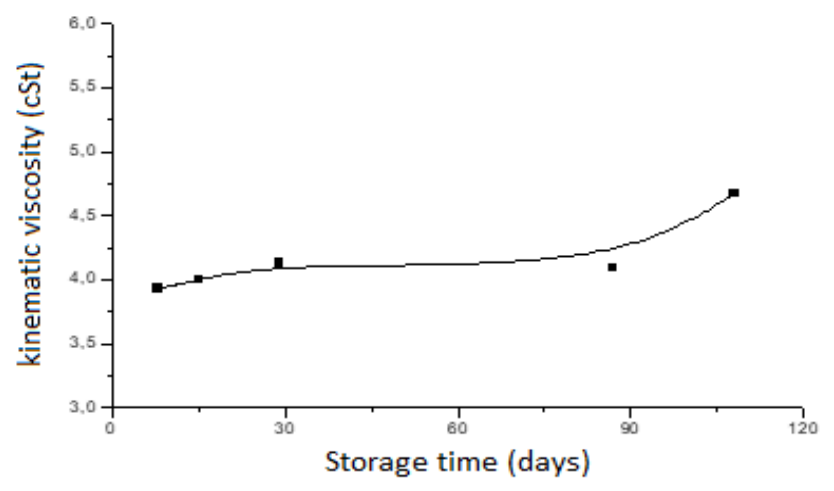

Figure 3: Kinematic viscosity as a function of time for biodiesel obtained from cottonseed oil at $70{ }^{\circ} \mathrm{C}$

Biodiesel viscosity increased over time, especially after 100 days of storage. This fact suggests the occurrence of a partial oxidation of biodiesel with formation of products that increase its viscosity. However, it is observed that even after a period of four months, the kinematic viscosity was still compatible with the range established by the ANP, unlike the acidity index behaviour.

\section{Gas Chromatography}

Table 1 shows the ester contents in biodiesel obtained from cottonseed oil at $70^{\circ} \mathrm{C}$, before and after storage in two separate vials. Even after thermo-oxidative treatment, biodiesel samples maintained the minimum ester content required by the ANP. However, there is a decrease in the percentage of esters in the range of C18: 1 to C18: 2 and an increase in the other ester ranges. The C18: 2 content refers to a chain of 18 carbon atoms and 2 unsaturations. Therefore, unsaturation tends to be preferentially oxidized over other carbon-carbon bonds.

There was little light contribution in the oxidation process, since there was no significant change between the results obtained with the samples stored in the amber and transparent vials.

TABLE I

ESTER CONTENTS IN COTTONSEED BIODIESEL OBTAINED AT $70^{\circ} \mathrm{C}$ (WT.\%)

\begin{tabular}{|c|c|c|c|}
\hline Sample & $\begin{array}{c}\text { Before } \\
\text { storage }\end{array}$ & $\begin{array}{c}\text { Amber } \\
\text { vial } \\
\text { (3 months) }\end{array}$ & $\begin{array}{c}\text { Transparent } \\
\text { vial (3 } \\
\text { months) }\end{array}$ \\
\hline $\mathrm{C}_{16} 6^{-}$ & 0.65 & --- & --- \\
\hline $\mathrm{C}_{16: 0}$ & 20.31 & 21.62 & 20.54 \\
\hline $\mathrm{C}_{18: 0}$ & 1.75 & 1.99 & 1.95 \\
\hline $\mathrm{C}_{18: 1}$ & $\mathbf{1 9 . 0 0}$ & $\mathbf{1 8 . 8 7}$ & $\mathbf{1 8 . 4 8}$ \\
\hline $\mathrm{C}_{18: 2}$ & $\mathbf{5 8 . 3 0}$ & $\mathbf{5 5 . 8 5}$ & $\mathbf{5 5 . 4 4}$ \\
\hline Total & 100.00 & 98.33 & 98.34 \\
\hline
\end{tabular}

where Cx:y(- ou +) indicates:

$\mathrm{x}=$ number of carbon atoms in the molecule

$\mathrm{y}=$ number of insaturations in the molecule

- = esters with structure lower than the cited one

\section{Stability tests}




\section{Precipitate formation}

Table 2 presents the results obtained for the stability test, which evaluated the effects of the presence of light and the heating time on the thermo-oxidative stability of biodiesel.

TABLE III

MASS OF PRECIPITATE FORMED AND REFRACTIVE INDEX OF BIODIESEL AFTER OXIDATION

\begin{tabular}{|c|c|c|c|c|}
\hline Sample & $\begin{array}{c}\text { Transparent } \\
\text { vial }\end{array}$ & $\begin{array}{c}\text { Amber } \\
\text { vial }\end{array}$ & $\begin{array}{c}\text { Amber } \\
\text { vial }\end{array}$ & $\begin{array}{c}\text { Amber } \\
\text { vial }\end{array}$ \\
\hline $\begin{array}{c}\text { Storage } \\
\text { time } \\
\text { (days) }\end{array}$ & 112 & 103 & 193 & 193 \\
\hline $\begin{array}{c}\text { Heating } \\
\text { time } \\
\text { (min) }\end{array}$ & 180 & 180 & 60 & 180 \\
\hline $\begin{array}{c}\text { Mass of } \\
\text { precipitat } \\
\text { e (g) }\end{array}$ & 0.0133 & 0.0136 & 0.0157 & 0.0190 \\
\hline $\begin{array}{c}\text { Refractio } \\
\mathrm{n} \text { index } \\
\text { (initial) }\end{array}$ & 1.4455 & 1.446 & 1.447 & 1.447 \\
\hline $\begin{array}{c}\text { Refractio } \\
\mathrm{n} \text { index } \\
\text { (after } \\
\text { test) }\end{array}$ & 1.451 & 1.450 & 1.451 & 1.452 \\
\hline
\end{tabular}

It can be observed that there is no influence of the exposure of the sample to light (storage in amber and transparent vials) in the presented results, since the differences between the masses and the refractive indexes values of the two samples are within the margin of error associated with the measurements. On the other hand, we can emphasize the influence of the heating time on the amount of precipitate formed. Although the formation of solid material was very small, a long exposure time of biodiesel at high temperatures should be avoided, as the instability due to sediment formation is quite worrying due to the possibility of obstruction of sensitive engine parts.

\section{Thermo-oxidative stability}

Figures 4 and 5 show variations in electrical conductivity and $\mathrm{pH}$, respectively, as a function of biodiesel heating time at $100{ }^{\circ} \mathrm{C}$ (sample previously stored in the amber vial). The increase in conductivity and the decrease in $\mathrm{pH}$ value (increase in acidity) are due to the release of volatile acid compounds during the biodiesel oxidation process. It is noted that conductivity increases rapidly with heating (Figure 4) from 100 minutes of testing.

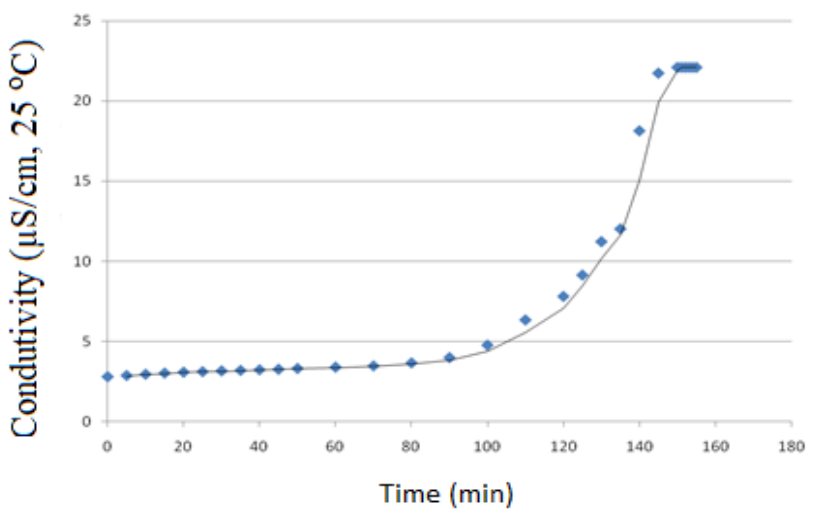

Figure 4: Variation of conductivity as a function of time (adapted EN 14112 test performed at $110^{\circ} \mathrm{C}$ )

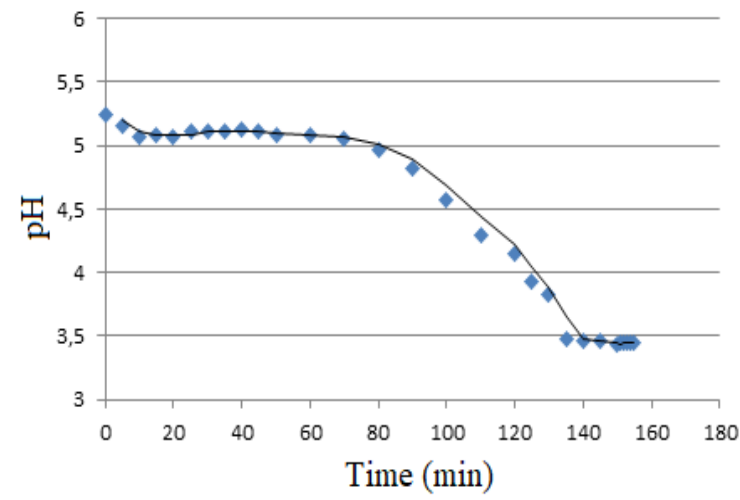

Figure 5: $\mathrm{pH}$ variation as a function of time (adapted EN 14112 test performed at $110^{\circ} \mathrm{C}$ )

Figures 6 and 7 show the variation of conductivity and $\mathrm{pH}$ as a function of time, respectively, performed at $25^{\circ} \mathrm{C}$. There is a practically linear relationship of both conductivity and $\mathrm{pH}$ as a function of time, although the effects are opposite (increased 
conductivity and decreased $\mathrm{pH}$ ). Therefore, a very distinct behavior in the variation of conductivity and $\mathrm{pH}$ as a function of the test conditions is observed: at $110^{\circ} \mathrm{C}$, a relatively long induction time (100 $\left.\mathrm{min}\right)$ is noted before there is variation in the conductivity and $\mathrm{pH}$. However, from this time on, conductivity and $\mathrm{pH}$ modify very rapidly. Conversely, variations in conductivity and $\mathrm{pH}$ occur slowly and gradually in the tests performed at $25^{\circ} \mathrm{C}$. This fact indicates different oxidation mechanisms of biodiesel as a function of the test temperature.

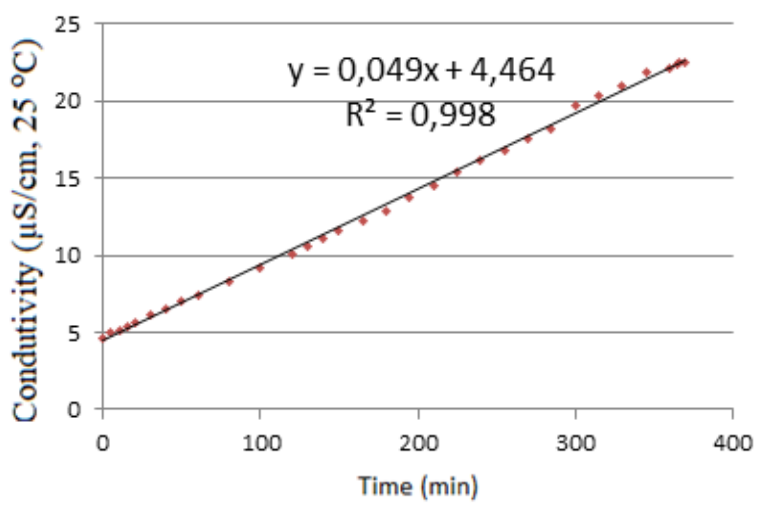

Figure 6: Variation of conductivity as a function of time (adapted EN 14112 test at $25^{\circ} \mathrm{C}$ )

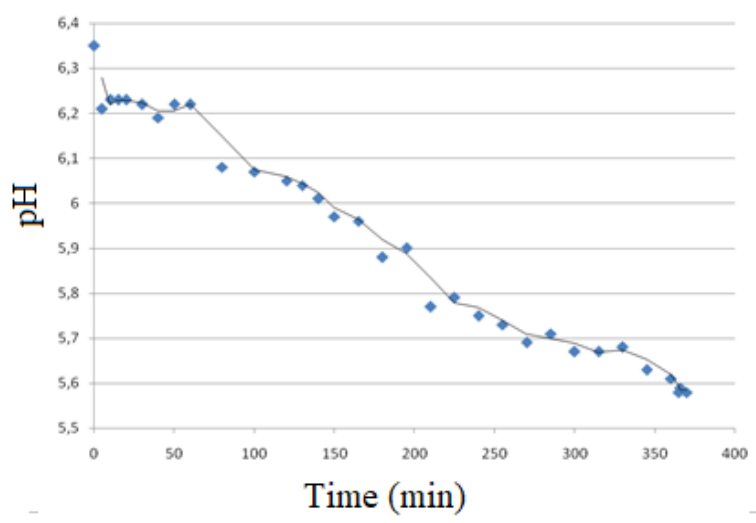

Figure 7: $\mathrm{pH}$ variation as a function of time (adapted EN 14112 test performed at $25^{\circ} \mathrm{C}$ )

\section{CONCLUSION}

The storage time influenced the acid properties of biodiesel, probably caused by the partial hydrolytic degradation of the samples. However, the lubricity characteristics of biodiesel were not affected by hydrolytic degradation. The photo degradation was little affected by the variations of the conditions employed in this work. Heating time affected the amount of precipitate formed during the oxidation process, but this precipitate did not change the biodiesel refractive index.

\section{REFERENCES}

[1]. F. R. Abreu, D. G. Lima, E. H. Hamú, C. Wolf, P. A. Z. Suarez. 2004. "Utilization of metal complexes as catalysts in the transesterification of Brazilian vegetable oils with different alcohols". Journal of Molecular Catalysis A: Chemical 209 (Feb 2004), p. 29-33. ISSN No: 1381-1169 DOI: 10.1016/j.molcata.2003.08.003

[2]. A. Bouaid, M. Martinez, J. Aracil, J. 2007. “Long storage stability of biodiesel from vegetable and used frying oils". Fuel 86 (Nov 2007), p. 25962602. ISSN No: 0016-2361 DOI: 10.1016/j.fuel.2007.02.014

[3]. Y. C. Liang, C. Y. May, C. S. Foon, M. A. Ngan, C. C. Hock, Y. Basiron. 2006. "The effect of natural and synthetic antioxidants on the oxidative stability of palm diesel". Fuel 85 (Apr 2006), p. 867-870. ISSN No: 0016-2361 DOI: 10.1016/j.fuel.2005.09.003

[4]. B. R. Moser, S. Z. Erhan. 2008. "Branched chain derivatives of alkyl oleates: Tribological, rheological, oxidation, and low temperature properties". Fuel 87 (Aug 2008), p. 2253-2257. ISSN No: 0016-2361 DOI: 10.1016/j.fuel.2008.01.005

[5]. J-Y. Park, D-K. Kim, J-P. Lee, S-C. Park, Y-J. Kim, J-S. Lee. 2008. "Blending effects of biodiesels on oxidation stability and low temperature flow properties". Bioresource 
Technology 99 (2008), p. 1196-1203. ISSN No: 0960-8524 DOI: 10.1016/j.biortech.2007.02.017

[6]. D. Singh, D. Sharma, S. L. Soni, S. Sharma, P. K. Sharma, A. Jhalani. 2020. "A review on feedstocks, production processes, and yield for different generations of biodiesel". Fuel 262 (Feb 2020), p. 116553. ISSN No: 0016-2361 DOI: 10.1016/j.fuel.2019.116553

[7]. J. Van Gerpen. 2005. "Biodiesel processing and production”. Fuel Processing Technology 86 (Jun 2005), p. 1097-1107. ISSN No: 0378-3820 DOI: 10.1016/j.fuproc.2004.11.005

[8]. L. C. Meher, D. Vidya Sagar, S. N. Naik. 2006. "Technical aspects of biodiesel production by transesterification-a review". Renewable \& Sustainable Energy Reviews 10 (Jun 2006), p. 248-268. ISSN No: 1364-0321 DOI: 10.1016/j.rser.2004.09.002

[9]. S. L. Dmytryshyn, A K. Dalai, S. T. Chaudhari, H. K. Mishra, M. J. Reaney. 2004. "Synthesis and characterization of vegetable oil derived esters: evaluation for their diesel additive properties”. Bioresource Technology 92 (Mar 2004), p. 55-64. ISSN No: 0960-8524 DOI: 10.1016/j.biortech.2003.07.009

[10]. G. Vicente, M. Martínez, J. Aracil. 2004. "Integrated biodiesel production: a comparison of different homogeneous catalysts systems". Bioresource Technology 92 (May 2004), p. 297305. ISSN No: 0960-8524 DOI: 10.1016/j.biortech.2003.08.014

[11]. R. A. Ferrari, V. S. Oliveira, A. Scabio. 2005. "Oxidative stability of biodiesel from soybean oil fatty acid ethyl esters". Scientia Agricola 62 (Jun 2005), p. 291-295. ISSN No: 1678-992X DOI: 10.1590/S0103-90162005000300014

[12]. O. N. Freitas, R. C. Rial, L. F. Cavalheiro, J. M. S. Barbosa, C. E. D. Nazário, L. H. Viana. 2020. "Evaluation of the oxidative stability and cold filter plugging point of soybean methyl biodiesel/bovine tallow methyl biodiesel blends". Industrial Crops and Products 140 (Nov 2019) 111667. ISSN No: 0926-6690 DOI: 10.1016/j.indcrop.2019.111667

\section{Cite this article as :}

Cynthia Fraga Scofield, Thiago V. Rodrigues, Caroline D. Oliveira, e Lucia R. Raddi de Araujo, "Study of Thermal and Oxidative Stability of Cottonseed Biodiesel", International Journal of Scientific Research in Science and Technology (IJSRST), Online ISSN : 2395-602X, Print ISSN : 2395-6011, Volume 6 Issue 6, pp. 282-288, November-December 2019. Available at doi https://doi.org/10.32628/IJSRST19661

Journal URL : http://ijsrst.com/IJSRST19661 